\title{
Reproductive performance of lactating dairy cows managed for first service using timed artificial insemination with or without detection of estrus using an activity-monitoring system
}

\author{
P. M. Fricke, ${ }^{1}$ J. O. Giordano, ${ }^{2}$ A. Valenza, G. Lopes Jr., M. C. Amundson, and P. D. Carvalho \\ Department of Dairy Science, University of Wisconsin, Madison 53706
}

\begin{abstract}
Lactating dairy cows $(\mathrm{n}=1,025)$ on a commercial dairy farm were randomly assigned at $10 \pm 3 \mathrm{~d}$ in milk (DIM) to 1 of 3 treatments for submitting cows to first artificial insemination (AI) and were fitted with activity-monitoring tags (Heatime; SCR Engineers Ltd., Netanya, Israel) at $24 \pm 3$ DIM. Cows $(\mathrm{n}=339)$ in treatment 1 were inseminated based on increased activity from the end of the voluntary waiting period (50 DIM) until submission to an Ovsynch protocol; cows without increased activity from 21 to 65 DIM began an Ovsynch protocol at $65 \pm 3$ DIM, whereas cows without increased activity from 21 to 50 DIM but not from 51 to 79 DIM began an Ovsynch protocol at $79 \pm 3$ DIM. Cows $(\mathrm{n}=340)$ in treatment 2 were inseminated based on activity after the second $\mathrm{PGF}_{2 \alpha}$ injection of a Presynch-Ovsynch protocol at 50 DIM, and cows without increased activity began an Ovsynch protocol at $65 \pm 3$ DIM. Cows $(\mathrm{n}=346)$ in treatment 3 were monitored for activity after the second $\mathrm{PGF}_{2 \alpha}$ injection of a Presynch-Ovsynch protocol, but all cows received timed AI (TAI) at $75 \pm 3$ DIM after completing the Presynch-Ovsynch protocol. The activity-monitoring system detected increased activity in 56,69 , and $70 \%$ of cows in treatments 1, 2, and 3 , respectively. Treatment- 2 cows had the fewest average days to first AI (62.5), treatment-3 cows had the most average days to first AI (74.9), and treatment-1 cows had intermediate average days to first AI (67.4). Treatment-1 and -2 cows in which inseminations occurred as a combination between increased activity and TAI had fewer overall pregnancies per AI (P/AI) 35 $\mathrm{d}$ after AI (32\% for both treatments) compared with treatment-3 cows, all of which received TAI after completing the Presynch-Ovsynch protocol (40\%). Based on survival analysis, although the rate at which cows
\end{abstract}

Received August 13, 2013.

Accepted February 11, 2014.

${ }^{1}$ Corresponding author: pmfricke@wisc.edu

${ }^{2}$ Current address: Department of Animal Science, Cornell University, Ithaca, NY 14850. were inseminated differed among treatments, treatment did not affect the proportion of cows pregnant by 300 DIM. Thus, use of an activity-monitoring system to inseminate cows based on activity reduced days to first AI, whereas cows receiving $100 \%$ TAI after completing a Presynch-Ovsynch protocol had more P/AI. The trade-off between $\mathrm{AI}$ service rate and $\mathrm{P} / \mathrm{AI}$ in the rate at which cows became pregnant was supported by an economic analysis in which the net present value $(\$ /$ cow per year) differed by only $\$ 4$ to $\$ 8$ among treatments. We conclude that a variety of strategies using a combination of AI based on increased activity using an activity-monitoring system and synchronization of ovulation and TAI can be used to submit cows for first AI. Key words: estrus detection, activity monitoring system, timed artificial insemination

\section{INTRODUCTION}

Although hormonal synchronization protocols that allow for timed AI (TAI) in lactating dairy cows have been widely adopted, AI based on detection of estrus plays an important role in the overall reproductive management program on most dairies in the United States (Caraviello et al., 2006; Miller et al., 2007). Increased physical activity is a secondary sign of estrus in cattle, and automated electronic systems that incorporate activity monitoring as a means to associate increased physical activity with estrous behavior and timing of AI in cattle have been developed and marketed to the dairy industry (Holman et al., 2011; Jónsson et al., 2011; Valenza et al., 2012). New technologies for detection of estrus, however, must be practically integrated into a systematic reproductive management strategy and empirically evaluated to determine the usefulness and economics of these technologies for improving reproductive performance. Although some experiments have assessed this new technology under field conditions (Neves et al., 2012; Valenza et al., 2012), within-farm treatment comparisons are needed to determine the efficacy and economic outcomes of the management strategies that combine detection of activity and synchronized breeding programs. 
Based on an analysis using 5,818 records from 13 studies in 8 dairy herds in the United States, the rate of anovulation in lactating Holstein cows averaged $23 \%$ at 50 to 65 DIM (Bamber et al., 2009), a time coinciding with the end of the voluntary waiting period (VWP) and onset of AI breeding to detected estrus or TAI, or both, in most herds. Furthermore, only $71 \%$ of lactating Holstein cows in which estrus was synchronized were detected with increased activity by an activitymonitoring system and ovulated (Valenza et al., 2012). Although anovular cows submitted to a protocol for synchronization of ovulation and TAI have reduced fertility and more pregnancy losses than their cycling herd mates (Santos et al., 2004a,b; Sterry et al., 2006), many anovular cows submitted to synchronization of ovulation and TAI conceive and maintain pregnancy. Thus, a combined approach in which insemination is based both on activity detected by an automated monitoring system followed by submission of cows not detected with activity to TAI after synchronization of ovulation may be an effective and economical strategy to submit lactating dairy cows for first AI.

Our objective was to compare reproductive performance of lactating dairy cows managed for first AI using TAI with or without detection of estrus using an activity-monitoring system on a commercial dairy farm. Three reproductive management strategies were compared to assess the percentage of cows detected with increased activity based on the activity-monitoring system and to assess the fertility of cows inseminated based on activity versus TAI after synchronization of ovulation. Our overall hypothesis was that reproductive performance would be similar among the 3 treatments. From a physiological perspective, our hypothesis was that cows inseminated based on detected activity after the second $\mathrm{PGF}_{2 \alpha}$ injection of a Presynch-Ovsynch protocol would have lower fertility compared with cows detected in estrus after the second $\mathrm{PGF}_{2 \alpha}$ injection of a Presynch-Ovsynch protocol but submitted to receive TAI after completing the protocol. Finally, we compared the economics of the 3 programs based on a simulation study using a decision-support system that accounts for the cost and revenue associated with different reproductive management programs for dairy herds (Giordano et al., 2012).

\section{MATERIALS AND METHODS}

\section{Cows, Housing, and Feeding}

This study was conducted from June 2011 to October 2012 on a commercial dairy farm milking approximately 1,000 cows located near Lancaster, Wisconsin. Lactating Holstein cows $(\mathrm{n}=1,025 ; 387$ primiparous and 638 multiparous) were enrolled into the study on a weekly basis. Cows were milked 3 times daily and were fed a TMR once daily that was formulated to meet or exceed minimum nutritional requirements for high-producing dairy cows (NRC, 2001). The rolling herd average of the farm during the experiment was approximately $44 \mathrm{~kg}$ of milk per cow per day, with $3.8 \%$ fat and $3.1 \%$ protein. Cows were housed in sandbedded freestall barns and were handled to receive hormonal injections for synchronization of estrus and ovulation and for inseminations using an automatic sort gate and palpation rail system after exiting the milking parlor. All cows received injections of bovine somatotropin (Posilac, 500 mg; Elanco Animal Health, Indianapolis, IN) at 14-d intervals beginning at approximately 60 DIM until dry-off. All procedures were approved by the Animal Care and Use Committee of the College of Agricultural and Life Sciences of the University of Wisconsin-Madison.

\section{Detection of Activity and Al}

Lactating dairy cows $(\mathrm{n}=1,025)$ were fitted with activity-monitoring tags (Heatime; SCR Engineers Ltd., Netanya, Israel) at $24 \pm 3$ DIM upon exiting the post-fresh pen. Before each milking, data collected by the activity-monitoring system was read by a transceiver unit placed on an archway at the milking parlor entrance and recorded by the activity-monitoring system software (Data Flow 1 version 4.7; SCR Engineers Ltd.) installed on an on-farm computer. All settings of the herd-management software were based on those being used by the farm at initiation of the experiment as described in detail elsewhere (Valenza et al., 2012). The software threshold to alert that cows were possibly in estrus was set at 4.7 , and software settings were not changed during the course of the experiment.

Inseminations were performed based on increased activity detected by the activity-monitoring system or TAI, according to the respective treatments (described below) by 2 herd inseminators. Twice daily (after the first $(0700$ to $0900 \mathrm{~h}$ ) and second (1400 to $1700 \mathrm{~h}$ ) milkings, a list of cows with activity levels that exceeded the system threshold to consider a cow in estrus was generated by the activity-monitoring system software. Individual cows were inseminated once based on activity or at a fixed time after a synchronization-of-ovulation protocol (i.e., TAI). Cows inseminated to increased activity were not reinseminated if they appeared on a subsequent list of cows to be inseminated. Inseminations based on synchronization of ovulation and TAI were conducted once per week. Ovulation was synchronized using $\mathrm{GnRH}(100 \mu \mathrm{g}$ of gonadorelin diacetate tetrahydrate; Fertagyl; Intervet Animal Health, Millsboro, 
$\mathrm{DE})$ and $\mathrm{PGF}_{2 \alpha}(25 \mathrm{mg}$ of dinoprost tromethamine; Lutalyse; Zoetis Animal Health, New York, NY).

\section{Treatments}

Cows were blocked by parity (primiparous vs. multiparous) at $10 \pm 3$ DIM and were randomly assigned to 1 of 3 treatments to receive their first AI (Figure 1). Cows assigned to the 3 treatments were comingled in pens within parity groups (primiparous vs. multiparous) because lactating cows were segregated by parity within pens.

Cows $(\mathrm{n}=339)$ in treatment 1 were continuously monitored for increased activity beginning $31 \mathrm{~d}$ postpartum (first $10 \mathrm{~d}$ to establish baseline activity for individual cows), and activity was recorded by the activity-monitoring system software. Cows with increased activity after the end of the VWP (50 DIM) were inseminated based on lists generated by the activitymonitoring system software, whereas cows not detected with increased activity (before and after the VWP) were submitted to an Ovsynch protocol (Brusveen et al., 2008; GnRH injection followed by $\mathrm{PGF}_{2 \alpha}$ injection 7 $\mathrm{d}$ later, GnRH injection $56 \mathrm{~h}$ after $\mathrm{PGF}_{2 \alpha}$ injection, and TAI 16 to $20 \mathrm{~h}$ later) at $65 \pm 3 \mathrm{DIM}$ and received TAI at $75 \pm 3$ DIM. Cows with at least 1 increased activ- ity period that occurred before the end of the VWP were considered to be cycling and, if not inseminated between 50 and $65 \pm 3$ DIM, were monitored until $79 \pm$ 3 DIM and inseminated based on increased activity. If not inseminated by $79 \pm 3$ DIM, cows were submitted to an Ovsynch protocol to receive TAI at $89 \pm 3$ DIM.

Cows $(\mathrm{n}=340)$ in treatment 2 were submitted to a Presynch-Ovsynch protocol by administering 2 i.m. injections of $\mathrm{PGF}_{2 \alpha} 14 \mathrm{~d}$ apart (Presynch) at $39 \pm 3$ and $53 \pm 3$ DIM to presynchronize their estrous cycles (Moreira et al., 2001). Cows with increased activity after the second $\mathrm{PGF}_{2 \alpha}$ injection were inseminated based on increased activity, whereas cows without increased activity initiated the Ovsynch portion of the protocol beginning $12 \mathrm{~d}$ after the second $\mathrm{PGF}_{2 \alpha}$ injection and received TAI at $75 \pm 3$ DIM.

Cows $(\mathrm{n}=346)$ in treatment 3 were submitted to the same Presynch-Ovsynch protocol as described for treatment 2 cows; however, treatment-3 cows with increased activity after the second $\mathrm{PGF}_{2 \alpha}$ injection of Presynch were recorded by the activity-monitoring system software but were not inseminated. Thus, all treatment-3 cows completed the Presynch-Ovsynch protocol and received TAI at $75 \pm 3$ DIM. Data from treatment-3 cows were categorized based on whether or not they were detected with increased activity by

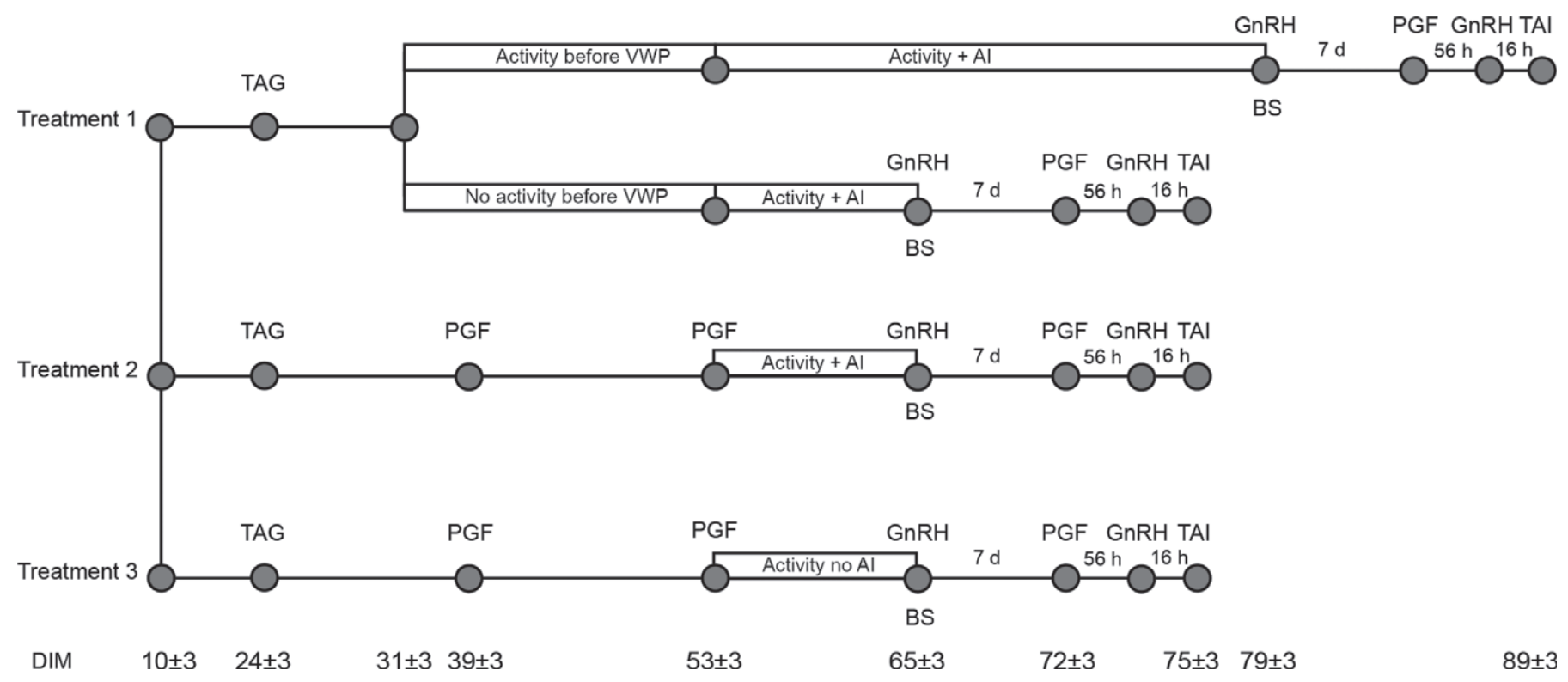

Figure 1. Schematic representation of experimental treatments. Cows were randomly assigned at $10 \pm 3$ DIM to 1 of 3 treatments for submitting cows to first AI and were fitted with an activity-monitoring tag (TAG) at $24 \pm 3$ DIM. Cows $(\mathrm{n}=339)$ in treatment 1 were inseminated based on increased activity from the end of the voluntary waiting period (VWP; $53 \pm 3$ DIM) until submission to an Ovsynch protocol; cows without increased activity from 21 to 65 DIM began an Ovsynch protocol at $65 \pm 3$ DIM, whereas cows without increased activity from 21 to 50 DIM but not from 51 to 79 DIM began an Ovsynch protocol at $79 \pm 3$ DIM and received TAI at $89 \pm 3$ DIM. Cows $(\mathrm{n}=340)$ in treatment 2 were inseminated based on activity after the second $\mathrm{PGF}_{2 \alpha}(\mathrm{PGF})$ injection of a Presynch-Ovsynch protocol at $53 \pm 3$ DIM, and cows without increased activity initiated an Ovsynch protocol at $65 \pm 3$ DIM. Cows $(\mathrm{n}=346)$ in treatment 3 were monitored for increased activity after the second PGF injection of a Presynch-Ovsynch protocol, but all cows received timed AI (TAI) at $75 \pm 3$ DIM after completing the PresynchOvsynch protocol. 
the activity-monitoring system after the second $\mathrm{PGF}_{2 \alpha}$ injection of the Presynch-Ovsynch protocol.

\section{Pregnancy Diagnosis}

Pregnancy diagnosis was performed by transrectal ultrasonography using a machine equipped with a 5.0$\mathrm{MHz}$ linear array transducer (Aloka 500V; Corometrics Medical Systems Inc., Wallingford, CT). Pregnancy status was evaluated by the herd veterinarian $35 \pm 3$ $\mathrm{d}$ after $\mathrm{AI}$, and cows diagnosed pregnant were reevaluated at $67 \pm 3 \mathrm{~d}$ after AI. A positive pregnancy diagnosis was based on visualization of an embryo with a heartbeat. The number of pregnancies per AI (P/AI) $35 \pm 3$ and $67 \pm 3 \mathrm{~d}$ after AI was calculated by dividing the number of cows diagnosed pregnant by the total number of cows inseminated. A cow was considered to have undergone pregnancy loss if confirmed pregnant at the initial pregnancy diagnosis and diagnosed not pregnant at the pregnancy reconfirmation or if detected in estrus and inseminated during the same time period.

\section{Blood Collection and Progesterone Analysis}

Blood samples were collected via puncture of the median caudal vein or artery into evacuated tubes (Vacuette; Greiner Bio-One North America Inc., Monroe, $\mathrm{NC}$ ) at the first $\mathrm{GnRH}$ injection of the Ovsynch protocol for cows in each treatment that were enrolled into an Ovsynch protocol. Blood samples were not collected from cows inseminated based on increased activity. Blood samples were immediately placed on ice, transported to the laboratory, and allowed to clot for 12 $\mathrm{h}$ at $4^{\circ} \mathrm{C}$. Clotted blood samples were centrifuged (1,935 $\times \mathrm{g}$ for $15 \mathrm{~min}$ at $4^{\circ} \mathrm{C}$ ), and serum was harvested and stored at $-20^{\circ} \mathrm{C}$ until assayed for progesterone $(\mathbf{P} 4)$ concentration using a solid-phase, no-extraction RIA (Coat-a-count, Diagnostic Products Cooperation, Los Angeles, CA). Sensitivity of the assay was $0.02 \mathrm{ng} / \mathrm{mL}$, and intraassay coefficients of variation were 2.3 and $4.1 \%$ for low $(2 \mathrm{ng} / \mathrm{mL})$ and high $(10 \mathrm{ng} / \mathrm{mL})$ quality control samples, respectively. Blood samples collected at the first $\mathrm{GnRH}$ injection were used to classify cows as having either high $(\geq 1 \mathrm{ng} / \mathrm{mL})$ or low $(<1 \mathrm{ng} / \mathrm{mL})$ $\mathrm{P} 4$ concentration at the first $\mathrm{GnRH}$ injection of the Ovsynch protocol.

\section{Statistical Analyses}

The experimental design was a complete randomized block design, with parity as the blocking factor. Analyses of binary response data (P/AI and pregnancy loss) were performed by logistical regression using PROC GLIMMIX of SAS (SAS Institute Inc., Cary, NC). For
$\mathrm{P} / \mathrm{AI} 35$ and $67 \mathrm{~d}$ after TAI, the initial model contained as fixed effects the following categorical explanatory variables: treatment, parity (primiparous vs. multiparous), AI technician (1 vs. 2), and breeding season (cool vs. warm) as well as the interaction between treatment and parity, and treatment and breeding season. Separate analyses were performed to evaluate differences in $\mathrm{P} / \mathrm{AI}$ at 35 and $67 \mathrm{~d}$ after AI. For both endpoints, one analysis included as a categorical variable the overall effect of treatment $(1,2$, and 3$)$, whereas a second analysis consisted of a model that contained as explanatory variable subgroups of cows created based on whether or not activity was detected by the activity-monitoring system. For the classification of inseminations by breeding season, inseminations from September 1, 2011, to May 31, 2012, were considered to occur during the cool season, whereas inseminations from June 1 to August 10, 2012, were considered to occur during the warm season. Selection of the model that best fit the data for each variable of interest was performed by finding the model with the lowest value for the Akaike information criterion (AIC) using a backward elimination procedure that removed all variables with $P>0.10$ from the model. Regardless of their significance level, both treatment and parity (a blocking factor used during the randomization process) were forced to remain in each model. An additional analysis of preplanned contrasts was performed with the CONTRAST option of PROC GLIMMIX of SAS to evaluate differences in P/AI at 35 d between parities (primiparous vs. multiparous within each treatment). For analysis of pregnancy loss from 35 to $67 \mathrm{~d}$ after AI, the same categorical variables and interactions used for $\mathrm{P} / \mathrm{AI}$ and the same procedures and criteria for model selection were used in the model. The final model for pregnancy loss included the effects of treatment and parity.

Data collected from subgroups of cows in treatments 1 and 2 that started the Ovsynch protocol and all cows in treatment 3 were used to determine differences in $\mathrm{P} 4$ concentrations at the first $\mathrm{GnRH}$ injection of the Ovsynch protocol by ANOVA using PROC MIXED of SAS and on the proportion of cows with or without a functional corpus luteum (P4 concentration $\geq 1 \mathrm{ng} /$ $\mathrm{mL}$ ) at the time of the first GnRH injection of the Ovsynch protocol by logistic regression using PROC GLIMMIX of SAS. The categorical variables included in the models were subgroup (cows with no activity in treatments 1 and 2 , and cows with and without activity in treatment 3) and parity.

Survival analysis was conducted to evaluate the effect of treatment on the hazard of first AI and pregnancy by 300 DIM by creating Cox semiparametric proportional hazard models using PROC PHREG of SAS. The outcome variable for the Cox model for first 
AI was DIM at first AI, whereas for pregnancy by 300 DIM it was the DIM at which cows conceived. Right censoring occurred for cows that left the herd due to live culling or death for the analysis of hazard of first $\mathrm{AI}$ and pregnancy by $300 \mathrm{DIM}$. The models for time to first AI and pregnancy included treatment, parity, and season as categorical explanatory variables and were selected as described for the models used to analyze $\mathrm{P} / \mathrm{AI}$. The PHREG procedure of SAS was used to test the time dependence of the effect of treatment in the Cox model of time to pregnancy at 300 DIM to justify use of full-lactation outcomes for experimental treatments imposed only for first AI. Kaplan-Meier survival analysis curves were constructed to illustrate the rate at which cows received first AI and conceived until 300 DIM by using the Kaplan-Meier survival analysis option of MedCalc (version 12.5.0.0; MedCalc Software bvba, Mariakerke, Belgium).

A significant difference between the levels of a classification variable was declared when $P<0.05$, whereas differences between $P \geq 0.05$ and $P \leq 0.10$ were considered a statistical tendency. The least significant difference post-hoc mean separation test was used to determine differences among treatments.

\section{Economic Analysis}

An economic analysis was performed to evaluate the net present value (NPV; \$/cow per year) for each treatment, using a software simulation tool developed based on a mathematical model combining Markov chain simulation with partial budgeting (Giordano et al., 2012). The economic analyses compared the NPV of each treatment for this particular farm and are not meant to be extrapolated to other farms. To simulate scenarios for a farm of similar characteristics to the farm where the study was performed, general descriptive parameters [number of cows $(1,000)$, cows leaving the herd per year for nonreproductive reasons $(28.5 \%)$, mortality rate $(6.0 \%)$, still birth rate $(10 \%)$, average BW $(658 \mathrm{~kg})$, and cut-off DIM to discontinue inseminating nonpregnant cows (330 DIM)], productive parameters (milk production by test number up to 405 DIM for cows of parity 1,2 , and $\geq 3$ ), and economic parameters [milk price $(\$ 0.40 / \mathrm{kg})$, feed costs $(\$ 0.29 / \mathrm{kg}$ of $\mathrm{DM})$, heifer replacement cost $(\$ 1,300)$, calf value $(\$ 175$ for females and $\$ 50$ for males), and salvage value of culled cows $(\$ 1.32 / \mathrm{kg}$ of $\mathrm{BW})]$, were extracted from onfarm computerized records (DairyCOMP 305; Valley Ag Software, Tulare, CA) and farm financial records. Values representative for the dairy industry, based on an economic database from the Center for Dairy Profitability at the University of Wisconsin-Madison, were used when no data was available from the farm.
The reproductive programs simulated for first AI were the treatments evaluated in the present experiment. For second and subsequent AI, the reproductive program consisted of a combination of AI based on increased activity using the activity-monitoring system with resynchronization of ovulation and TAI using an Ovsynch protocol initiated $39 \pm 3 \mathrm{~d}$ after AI for cows that failed to conceive to AI and were not inseminated based on activity. Input parameters for the percentage of cows receiving AI based on activity and TAI for first AI were those reported in the present experiment, whereas for second and subsequent AI the values observed on the farm during the same time period when the experiment was performed were used $(76 \%$ of cows artificially inseminated based on activity, with $\mathrm{P} / \mathrm{AI}$ of $23 \%$, and $24 \%$ of cows receiving TAI after resynchronization of ovulation, with $\mathrm{P} / \mathrm{AI}$ of $28 \%$ ). Assumptions in the model regarding the activity-monitoring system included an initial cost of $\$ 10,000$ for hardware and installation, a cost of $\$ 100$ per activity tag for $50 \%$ of the cows in the herd, a 7-yr lifespan for the system, and a $10 \%$ salvage value at the end of the activity-monitoring system lifespan. The cost of GnRH was set at $\$ 2.00$, $\mathrm{PGF}_{2 \alpha}$ at $\$ 2.50$, AI (including semen and labor) $\$ 15.00$, and the cost of nonpregnancy diagnosis by transrectal ultrasonography at $\$ 125.00$ per hour.

\section{RESULTS AND DISCUSSION}

\section{Treatments}

The rate at which cows become pregnant (i.e., pregnancy rate) in a dairy herd is determined by an interaction between the rate at which cows are inseminated (i.e., the AI service rate) and the proportion of inseminated cows that become pregnant (i.e., $\mathrm{P} / \mathrm{AI}$ ). The AI service rate and $\mathrm{P} / \mathrm{AI}$ equally contribute to pregnancy rate, and both the AI service rate and $\mathrm{P} /$ AI can be affected by management strategies, including the use of activity-monitoring systems and hormonal synchronization protocols and TAI.

This experiment compared 3 strategies for submitting lactating dairy cows for first AI on a commercial dairy farm and is novel because it compared reproductive performance of cows managed using TAI with or without detection of estrus using an activity-monitoring system. Treatment 1 was included as a strategy for submission of cows to first AI using the least amount of hormonal intervention. Cows were allowed $12 \mathrm{~d}$ to be detected with increased activity by the activitymonitoring system, and only cows without activity during the VWP and this 12-d period were submitted to an Ovsynch protocol concurrent with initiation of Ovsynch in the Presynch-Ovsynch protocols in treat- 
ments 2 and 3 (Figure 1). To maintain the least amount of hormonal intervention, any cows in treatment 1 with increased activity before the end of the VWP were allowed additional time to express increased activity before enrollment into an Ovsynch protocol at 79 \pm 3 DIM (i.e., 24 d). Our rationale was that cycling cows should be allowed maximal opportunity to be detected with increased activity before enrollment into an Ovsynch protocol, thereby minimizing hormonal intervention; however, we also wanted to balance detection of activity with aggressive insemination for cows without activity as early as possible after the end of the VWP. A total of 33 cows originally randomized into the treatments $(11,7$, and 15 for treatments 1,2 , and 3 , respectively) were excluded from the analysis of first AI because they were sold or died before receiving an insemination. Only $18 \%$ of cows $(n=60)$ in treatment 1 were detected with increased activity before the end of the VWP but did not have increased activity from 50 to 65 DIM, and these cows were inseminated to activity between 65 to 79 DIM. Only $8 \%$ of cows $(\mathrm{n}=25)$ in treatment 1 were detected with increased activity before the end of the VWP, failed to be detected with increased activity from the end of the VWP until 79 DIM, and were then enrolled into an Ovsynch protocol at $79 \pm 3$ DIM and received TAI at $89 \pm 3$ DIM. For clarity of presentation, cows in treatment 1 were classified as either receiving AI based on increased activity using the activity-monitoring system or TAI after synchronization of ovulation using an Ovsynch protocol, regardless of whether TAI occurred at 75 or 89 DIM.

Treatment 2 was included to represent a widely used strategy for submission of cows to first AI on farms in North America. A presynchronization strategy in which cows receive 2 injections of $\mathrm{PGF}_{2 \alpha}$ administered $14 \mathrm{~d}$ apart (i.e., Presynch) and initiation of Ovsynch 12 $\mathrm{d}$ later increased P/AI to first TAI in lactating dairy cows compared with Ovsynch alone (Moreira et al., 2001). This synchronization protocol is commonly referred to as a Presynch-Ovsynch protocol, and has been widely adopted by dairy farms because of the ability to combine $\mathrm{AI}$ to estrus after the second $\mathrm{PGF}_{2 \alpha}$ injection, with cows not detected in estrus submitted to synchronization of ovulation and TAI.

Treatment 3 was included to compare $\mathrm{P} / \mathrm{AI}$ of cows with increased activity after presynchronization that were not inseminated based on activity but completed the Presynch-Ovsynch protocol and received TAI. Based on economic modeling, farms with poor $\mathrm{P} / \mathrm{AI}$ for cows inseminated to estrus after the second $\mathrm{PGF}_{2 \alpha}$ injection of a Presynch-Ovsynch protocol would be better off to forgo detection of estrus and allow all cows to complete the Presynch-Ovsynch protocol and receive TAI (Giordano et al., 2012). Thus, some farms choose to submit all cows to first TAI using a Presynch-Ovsynch protocol rather than inseminating cows to estrus after the second $\mathrm{PGF}_{2 \alpha}$ injection.

\section{Al Service Rate and P/AI}

Overall, treatment differences in days to first AI are reflected in the respective management strategies of each treatment, with treatment 1 and 2 cows inseminated earlier to increased activity, followed by Ovsynch and TAI, compared with treatment 3 cows in which AI was delayed by design until after completion of the Presynch-Ovsynch protocol and TAI. Survival analysis of days to first AI with Cox proportional regression indicated that the hazard of first insemination differed $(P<0.0001)$ among the 3 treatments (Figure 2 ). Treatment- 1 cows were inseminated at a lesser rate than treatment- 2 cows [hazard ratio $(\mathbf{H R})=0.60 ; 95 \%$ $\mathrm{CI}=0.51-0.70]$, but at a greater rate than treatment-3 cows $(\mathrm{HR}=1.55 ; 95 \% \mathrm{CI}=1.32-1.81)$, whereas treatment-2 cows were inseminated at a greater rate than treatment-3 cows $(\mathrm{HR}=2.59 ; 95 \% \mathrm{CI}=2.21-3.02)$. This difference in the hazard of insemination was reflected by a difference $(P<0.001)$ in median days to first AI among cows in the 3 treatments (median days to first AI were 68,59 , and $75 \mathrm{~d}$ for cows in treatments 1,2 , and 3 , respectively). Thus, incorporation of AI to increased activity based on the activity-monitoring system decreased the interval to first AI, thereby increasing the AI service rate compared with $100 \%$ TAI after a Presynch-Ovsynch protocol. The difference of about $13 \mathrm{~d}$ in days to first AI between treatment-2 and -3 cows in in the present study is similar to that reported in another experiment with a similar design but based on detection of estrus based on tail chalk (Chebel and Santos, 2010). In addition, both parity and season of breeding affected rate of first AI. Primiparous cows were inseminated at a greater rate $(P=0.008)$ than multiparous cows $(\mathrm{HR}=1.19 ; 95 \% \mathrm{CI}=1.05-1.36)$, whereas cows were inseminated at a greater rate $(P<$ 0.001 ) during the cool than the warm season of the year $(\mathrm{HR}=1.36 ; 95 \% \mathrm{CI}=1.17-1.58)$.

Conversely, Cox proportional analysis of days to pregnancy from the end of the VWP until 300 DIM indicated that treatment did not affect $(P=0.38)$ the rate at which cows became pregnant (Figure 3). The hazard of pregnancy for treatment-1 cows was 0.89 (95\% $\mathrm{CI}=0.76-1.05)$ and $0.96(95 \% \mathrm{CI}=0.81-1.13)$ of that of treatment-2 and -3 cows, respectively. The hazard of pregnancy for treatment-2 cows was 1.07 (95\% CI = $0.91-1.26)$ of that of treatment-3 cows. Treatment did not $(P=0.25)$ affect median days to pregnancy $(103$, 102, and 102 for treatment 1, 2, and 3, respectively). Parity and season of AI also affected the rate at which 


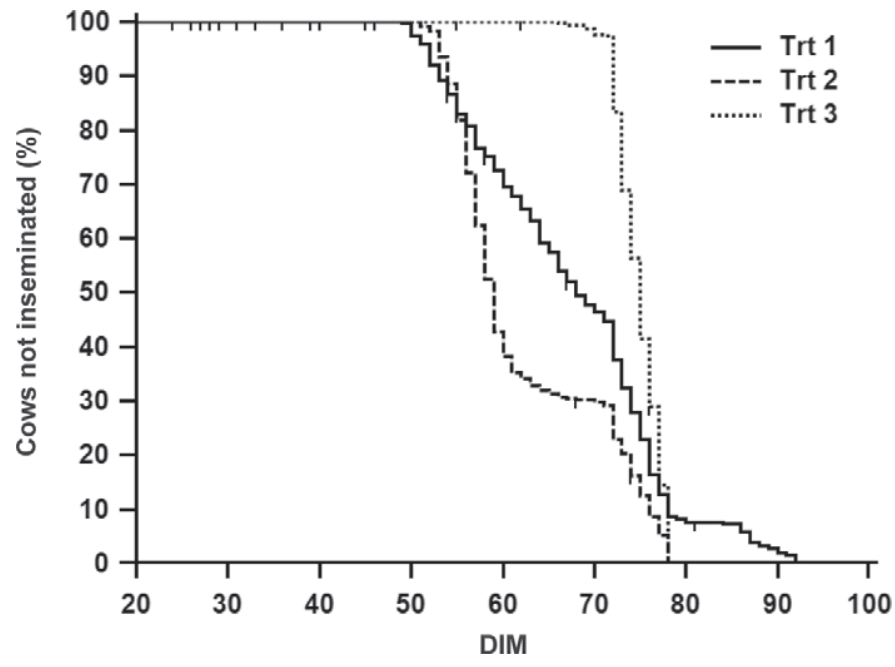

Figure 2. Kaplan-Meier survival analysis illustrating the effect of treatment on time to first AI. Cox proportional analysis of the time to first AI service after the end of the voluntary waiting period indicated that the hazard of first insemination differed $(P<0.0001)$ among treatments. Treatment-1 cows received AI at a lesser rate than treatment- 2 cows [hazard ratio $(\mathrm{HR})=0.60 ; 95 \% \mathrm{CI}=0.51-0.70]$ but at a greater rate than treatment-3 cows $(\mathrm{HR}=1.55 ; 95 \% \mathrm{CI}=1.32$ 1.81), whereas treatment-2 cows received $\mathrm{AI}$ at a greater rate than treatment-3 cows $(\mathrm{HR}=2.59 ; 95 \% \mathrm{CI}=2.21-3.02)$. Treatment affected $(P<0.001)$ median days to first AI $(68,59$, and $75 \mathrm{~d}$ for treatment-1, -2 , and -3 cows, respectively). Treatments were (1) cows inseminated to increased activity based on an activity-monitoring system, with cows not detected with activity receiving TAI after synchronization of ovulation using an Ovsynch protocol; (2) cows inseminated to increased activity based on an activity-monitoring system after a presynchronization protocol, with cows not detected with activity receiving TAI after synchronization of ovulation using an Ovsynch protocol; and (3) cows receiving TAI after a Presynch-Ovsynch protocol. Trt $=$ treatment.

cows became pregnant. Primiparous cows conceived at a greater rate $(P<0.001)$ than multiparous cows (HR $=1.42 ; 95 \% \mathrm{CI}=1.24-1.63)$, whereas cows became pregnant at a greater rate $(P=0.002)$ during the cool compared with the warm season of the year $(\mathrm{HR}=$ $1.28 ; 95 \%$ CI $=1.09-1.50$ ).

Although treatments in this study were focused on first AI, the period of analysis for days to pregnancy was set at 300 DIM to account for potential treatment differences in the pattern of reinsemination for cows failing to conceive to first AI. The treatment by time interaction was not significant $(P>0.1)$ based on a test of the time dependence of the effect of treatment in the Cox model of time to pregnancy at 300 DIM, thereby justifying the use of full-lactation outcomes for experimental treatments imposed only for first AI in the present study. Unlike treatment- 1 and -2 cows, which were eligible to be reinseminated if detected with increased activity any time after first AI, treatment-3 cows were not eligible to be reinseminated until after $75 \pm 3$ DIM. In addition, a consistent pattern of reinsemination with the majority of cows receiving second AI at almost 100 DIM (75 DIM first AI plus $23 \mathrm{~d}$ average duration of the estrous cycle) was expected for treatment-3 cows due to the high level of synchrony among the estrous cycles in these cows. The lack of a treatment effect in the proportion of cows pregnant at 300 DIM illustrates the trade-off between DIM at first AI (i.e., service rate) and the increased P/AI to TAI (i.e., fertility).

The activity-monitoring system detected increased activity in $56 \%$ of treatment- 1 cows and $69 \%$ and $70 \%$ of treatment- 2 and -3 cows, respectively (Table 1 ). In agreement with these results, approximately 55 to $60 \%$ of cows presynchronized with 2 injections of $\mathrm{PGF}_{2 \alpha}$ were detected in estrus using tail chalk after the second $\mathrm{PGF}_{2 \alpha}$ injection but before beginning an Ovsynch protocol (Stevenson and Phatak, 2005; Chebel et al., 2010; Chebel and Santos, 2010). Thus, about $40 \%$ of cows subjected to detection of estrus using tail chalk either failed to express estrus or failed to be detected in estrus, whereas only about $30 \%$ of cows in the present experiment failed to be detected with increased activity using the activity-monitoring system. These data suggest that an activity-monitoring system may detect

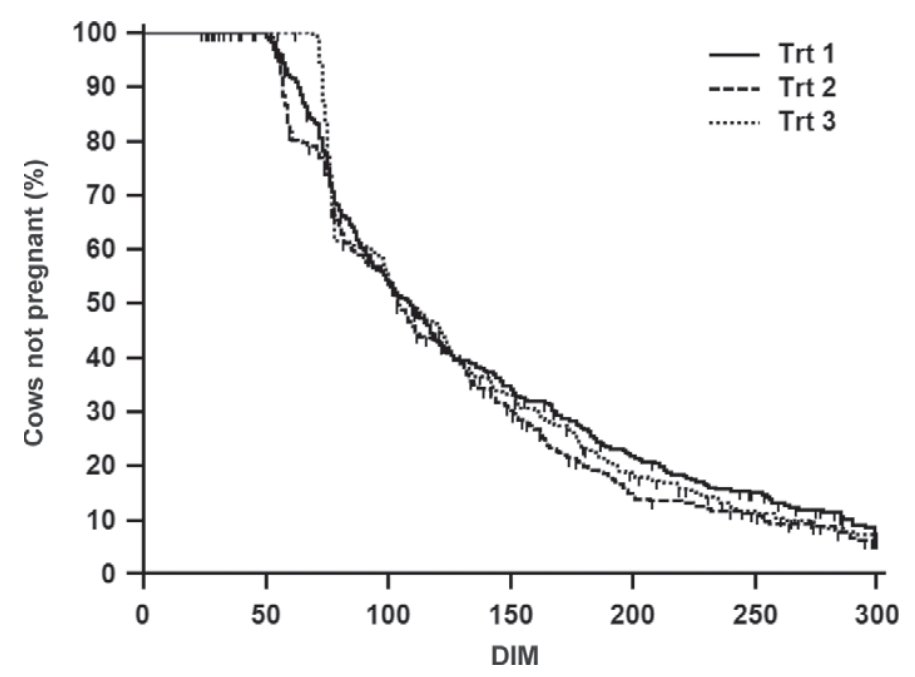

Figure 3. Kaplan-Meier survival analysis illustrating the effect of treatment on time to pregnancy. Cox proportional analysis of time to pregnancy determined that the hazard ratio for pregnancy to 300 DIM was similar $(P=0.38)$ among cows in the 3 treatments. The hazard ratio for pregnancy for treatment-1 versus treatment-2 cows was 0.89 $(95 \% \mathrm{CI}=0.76-1.05)$, treatment-1 versus treatment- 3 cows was 0.96 $(95 \% \mathrm{CI}=0.81-1.13)$, and treatment-2 versus treatment-3 cows was $1.07(95 \% \mathrm{CI}=0.91-1.26)$. Treatment did not affect $(P=0.25)$ median days to pregnancy $(103,102$, and $102 \mathrm{~d}$ for treatment-1, -2 , and -3 cows, respectively). Treatments were (1) cows inseminated to increased activity based on an activity-monitoring system, with cows not detected with activity receiving TAI after synchronization of ovulation using an Ovsynch protocol; (2) cows inseminated to increased activity based on an activity-monitoring system after a presynchronization protocol, with cows not detected with activity receiving TAI after synchronization of ovulation using an Ovsynch protocol; and (3) cows receiving TAI after a Presynch-Ovsynch protocol. Trt $=$ treatment. 
more cows in estrus compared with a tail-chalking system. Based on an analysis using 5,818 records from 13 studies in 8 dairy herds in the United States, the rate of anovulation in lactating Holstein cows averaged $23.3 \%$ at 50 to 65 DIM, with a range among herds of 7.3 to $41.7 \%$ (Bamber et al., 2009). Anovular cows have reduced fertility and more pregnancy losses compared with their cycling herd mates (Santos et al., 2004a,b; Sterry et al., 2006; Silva et al., 2007), but submission to a hormonal synchronization protocol results in some of these cows conceiving and maintaining pregnancy despite their anovular condition. Thus, anovular cows represent a subpopulation of cows at the end of the VWP that will not be detected in estrus but can conceive and maintain pregnancy after synchronization of ovulation and TAI.

Treatment-1 and -2 cows in which inseminations occurred as a combination between detection of increased activity and TAI had fewer $(P=0.004)$ overall $\mathrm{P} / \mathrm{AI}$ compared with treatment-3 cows that received TAI after completing the Presynch-Ovsynch protocol (Table 1). This difference in $\mathrm{P} / \mathrm{AI}$ must be interpreted with caution because it is confounded with DIM at AI, with treatment-3 cows inseminated later than treatment-1 and -2 cows. Although insemination of cows with increased activity after presynchronization decreased average days to first AI (Table 1), it may also decrease or eliminate the effect of presynchronization on P/AI. Our results in which cows submitted to a Presynch-Ovsynch protocol and TAI had more P/AI compared with cows inseminated to increased activity after presynchronization agree with those of Gumen et al. (2012) but do not agree with others who reported no difference in $\mathrm{P} /$ AI based on whether or not cows were inseminated to estrus after the second $\mathrm{PGF}_{2 \alpha}$ injection of a PresynchOvsynch protocol (Stevenson and Phatak, 2005; Chebel and Santos, 2010). Neves et al. (2012) reported that overall reproductive performance was similar between cows inseminated to increased activity versus TAI using the same activity-monitoring system used in the present experiment, but that differences in reproductive performance did occur among herds.

Cows in all 3 treatments without increased activity and submitted to an Ovsynch protocol had P/AI of 33 to $35 \%$ (Table 1). In addition to the effect of treatment on $\mathrm{P} / \mathrm{AI}$, a season by parity interaction $(P<0.01)$ on $\mathrm{P} / \mathrm{AI}$ existed in which multiparous cows had fewer P/ AI during the warm versus the cool season (34 vs. 15\%, respectively), whereas primiparous cows had similar P/ AI during the warm and the cool season (39 vs. $41 \%$, respectively). We reported a similar season by parity interaction on $\mathrm{P} / \mathrm{AI}$ in another experiment conducted on this farm (Valenza et al., 2012). Treatment-2 cows inseminated to activity after the second $\mathrm{PGF}_{2 \alpha}$ injection of the presynchronization protocol had fewer $(P$ $=0.004) \mathrm{P} / \mathrm{AI} 35 \mathrm{~d}$ after AI (30\%) compared with

Table 1. Effect of treatment on percentage of lactating Holstein cows with increased activity based on an activity-monitoring system, and pregnancies per AI (P/AI) and pregnancy losses for cows with or without activity and inseminated to activity (AI) or inseminated to timed AI (TAI) after synchronization of ovulation

\begin{tabular}{|c|c|c|c|}
\hline \multirow[b]{2}{*}{ Item } & \multicolumn{3}{|c|}{ Treatment $^{1}$} \\
\hline & 1 & 2 & 3 \\
\hline Cows with increased activity [\% (no./total no.)] & $56(183 / 328)$ & $69(230 / 335)$ & $70(232 / 331)$ \\
\hline \multicolumn{4}{|l|}{ P/AI 35 d after AI [\% (no./total no.)] } \\
\hline Cows with activity receiving AI & $30(55 / 183)$ & $30^{\mathrm{a}}(68 / 230)$ & 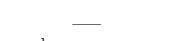 \\
\hline Cows with activity receiving TAI & - & - & $41^{\mathrm{b}}(96 / 232)$ \\
\hline Cows with no activity receiving TAI & $34(49 / 144)$ & $36(37 / 104)$ & $35(35 / 99)$ \\
\hline Overall P/AI 35 d after AI [\% (no./total no.)] & $32^{\mathrm{c}}(104 / 328)$ & $32^{\mathrm{c}}(105 / 333)$ & $40^{\mathrm{d}}(131 / 331)$ \\
\hline \multicolumn{4}{|l|}{ P/AI $67 \mathrm{~d}$ after AI [\% (no./total no.)] } \\
\hline Cows with activity receiving AI & $28(51 / 183)$ & $27(62 / 230)$ & - \\
\hline Cows with activity receiving TAI & - & - & $40(92 / 232)$ \\
\hline Cows with no activity receiving TAI & $33(48 / 144)$ & $33(34 / 104)$ & $35(35 / 99)$ \\
\hline Overall P/AI 67 d after AI [\% (no./total no.)] & $30^{\mathrm{c}}(99 / 328)$ & $29^{\mathrm{c}}(96 / 333)$ & $38^{\mathrm{d}}(127 / 331)$ \\
\hline \multicolumn{4}{|l|}{ Pregnancy loss from 35 to $67 \mathrm{~d}[\%$ (no./total no.) } \\
\hline Cows with activity receiving AI & $7(4 / 55)$ & $9(6 / 68)$ & - \\
\hline Cows with activity receiving TAI & - & - & $4(4 / 96)$ \\
\hline Cows with no activity receiving TAI & $2(1 / 49)$ & $8(3 / 37)$ & $0(0 / 35)$ \\
\hline Overall pregnancy loss $[\%$ (no./total no.) $]$ & $5(5 / 104)$ & $9(9 / 105)$ & $3(4 / 131)$ \\
\hline
\end{tabular}

${ }^{\mathrm{a}, \mathrm{b}}$ Within a treatment by activity subgroup, percentages with different superscript letters differ $(P<0.01)$.

${ }^{\mathrm{c}, \mathrm{d}}$ Within a row, percentages with different superscript letters differ $(P<0.01)$.

${ }^{1}$ Treatments were (1) cows inseminated based on an activity-monitoring system, with cows not detected with activity receiving TAI after synchronization of ovulation using an Ovsynch protocol; (2) cows inseminated based on an activity-monitoring system after a presynchronization protocol, with cows not detected with activity receiving TAI after synchronization of ovulation using an Ovsynch protocol; and (3) cows receiving TAI after a Presynch-Ovsynch protocol. 
treatment-3 cows with increased activity after the second $\mathrm{PGF}_{2 \alpha}$ injection of the presynchronization protocol that were not inseminated to activity but completed the Presynch-Ovsynch protocol and received TAI (41\%). These data support our hypothesis that cows inseminated after a Presynch-Ovsynch protocol would have had more $\mathrm{P} / \mathrm{AI}$ had they not been inseminated to increased activity but rather completed the PresynchOvsynch protocol.

One mechanism by which presynchronization may improve $\mathrm{P} / \mathrm{AI}$ is by manipulating the estrous cycle so that cows initiate the first injection of the Ovsynch protocol at a specific stage of the cycle. Initiation of Ovsynch on d 5 to 9 of the estrous cycle in lactating dairy cows resulted in a greater synchronization rate and more $\mathrm{P} /$ AI compared with other stages of the cycle (Vasconcelos et al., 1999). Although inseminating cows after the second $\mathrm{PGF}_{2 \alpha}$ injection of the Presynch-Ovsynch protocol decreased days to first AI, it also resulted in fewer P/AI by removing the presynchronized cows from the Ovsynch portion of the protocol and subsequent TAI. In addition, timing of AI in relation to ovulation is more precise among cows after synchronization of ovulation and TAI compared with cows inseminated based on increased activity in which the timing of AI in relation to ovulation is highly variable (Valenza et al., 2012).

A tendency $(P=0.1)$ was detected for a treatment by parity interaction on P/AI $35 \mathrm{~d}$ after AI (Table 2). Primiparous cows in treatment 2 had an overall $\mathrm{P} / \mathrm{AI}$ of $32 \%$ when inseminated based on increased activity after presynchronization followed by Ovsynch and TAI compared with primiparous cows in treatment 3 that had a P/AI of $49 \%$ when all cows received TAI after the Presynch-Ovsynch protocol. In contrast to our results, another study (Gumen et al., 2012) did not report an effect of parity using the same Presynch-Ovsynch protocol with detection of estrus, possibly due to the limited number of cows evaluated. Thus, choosing not to inseminate primiparous cows detected in estrus after presynchronization would have resulted in a 15 percentage point increase in $\mathrm{P} / \mathrm{AI}$ in the present experiment. By contrast, the overall $\mathrm{P} / \mathrm{AI}$ for multiparous cows in treatments 2 and 3 were similar.

\section{P4 Concentration at the First GnRH Injection of Ovsynch}

Overall, $44 \%$ of treatment- 1 cows, $31 \%$ of treatment- 2 cows, and $100 \%$ of treatment- 3 cows were submitted to an Ovsynch protocol (Table 3). In the present study, blood samples were collected from a subgroup ( $85 \%)$ of cows in each treatment at the first GnRH injection of the Ovsynch protocol to determine $\mathrm{P} 4$ concentration at
Table 2. Effect of treatment and parity on pregnancies per AI (P/AI) $35 \pm 3 \mathrm{~d}$ after AI in lactating Holstein cows

\begin{tabular}{llcc}
\hline & \multicolumn{2}{c}{ Parity [\% (no./total no.)] } & \\
\cline { 2 - 3 } Treatment $^{1}$ & Primiparous & Multiparous & P-value \\
\hline 1 & $39(49 / 127)$ & $27(55 / 201)$ & 0.034 \\
2 & $32(41 / 127)$ & $31(64 / 206)$ & 0.78 \\
3 & $49(63 / 129)$ & $34(68 / 202)$ & 0.006 \\
Overall & $40(153 / 383)$ & $31(187 / 609)$ & 0.003 \\
\hline
\end{tabular}

${ }^{1}$ Treatments were (1) cows inseminated based on an activity-monitoring system, with cows not detected with activity receiving TAI after synchronization of ovulation using an Ovsynch protocol; (2) cows inseminated based on an activity-monitoring system after a presynchronization protocol, with cows not detected with activity receiving TAI after synchronization of ovulation using an Ovsynch protocol; and (3) cows receiving TAI after a Presynch-Ovsynch protocol.

the onset of the protocol (Table 3). Treatment-1 cows had the highest P4 concentration at the first $\mathrm{GnRH}$ injection of Ovsynch, possibly because these cows were not subjected to hormonal presynchronization beforehand and were at later stages of their estrous cycles at the first $\mathrm{GnRH}$ injection. Treatment-3 cows with increased activity after presynchronization had higher $(P<0.001) \mathrm{P} 4$ concentrations at the first $\mathrm{GnRH}$ injection of Ovsynch than cows without activity after presynchronization.

Surprisingly, P4 concentrations for treatment-2 cows that were subjected to detection of activity after presynchronization and before beginning an Ovsynch protocol were high, with over $50 \%$ of these cows having $\mathrm{P} 4$ concentration $\geq 1 \mathrm{ng} / \mathrm{mL}$ at the first $\mathrm{GnRH}$ injection of Ovsynch. Similar results were observed for treatment-3 cows that were not detected with activity after presynchronization. If the efficiency of detection of estrus by the activity-monitoring system was high, most cows should by definition be anestrus and have low $\mathrm{P} 4$ concentration at the first GnRH injection of the Ovsynch protocol. In agreement with this observation, the presence of an activated Heatmount detector (Kamar Inc., Steamboat Springs, CO) after a similar presynchronization protocol had little relationship with circulating concentrations of P4 (Stevenson et al., 2008). In one experiment, only $68 \%$ of cows were inseminated to estrus after presynchronization using $2 \mathrm{PGF}_{2 \alpha}$ injections, yet some of the cows not detected in estrus were classified as cycling based on P4 concentration (Chebel and Santos, 2010). Those authors speculated that issues other than cyclicity status affected efficiency and accuracy of detection of estrus. In another study using the same activity-monitoring system (Valenza et al., 2012 ), about $10 \%$ of cows in which estrus was synchronized using a GnRH injection followed $7 \mathrm{~d}$ later by a $\mathrm{PGF}_{2 \alpha}$ injection ovulated but were not detected with increased activity. Based on these data, many 
Table 3. Effect of treatment on percentage of lactating Holstein cows receiving timed AI (TAI) after synchronization of ovulation, mean progesterone (P4) concentration at the first GnRH injection (G1) of the Ovsynch protocol, percentage of cows with high P4 concentration ( $\geq 1$ $\mathrm{ng} / \mathrm{mL}$ ) at $\mathrm{G1}$, and P/AI and pregnancy losses for cows with or without activity based on an activity-monitoring system

\begin{tabular}{|c|c|c|c|}
\hline Item & \multicolumn{3}{|c|}{ Treatment $^{1}$} \\
\hline Cows receiving TAI [\% (no./total no.)] & $44(144 / 327)$ & $31(105 / 335)$ & $100(331 / 331)$ \\
\hline \multicolumn{4}{|l|}{ Mean P4 concentration at $\mathrm{G} 1(\mathrm{ng} / \mathrm{mL})$} \\
\hline $\mathrm{n}$ & 125 & 87 & 287 \\
\hline Cows with activity $(\mathrm{n}=205)$ & - & - & $2.6 \pm 1.9^{\mathrm{b}}$ \\
\hline Cows without activity & $3.2 \pm 2.9^{\mathrm{a}}$ & $2.1 \pm 2.0^{\mathrm{bc}}$ & $1.7 \pm 1.7^{\mathrm{c}}$ \\
\hline
\end{tabular}

${ }^{\mathrm{a}-\mathrm{c}}$ Within a treatment by activity subgroup, means with different superscript letters differ $(P<0.01)$.

${ }^{\mathrm{x}, \mathrm{y}}$ Within a treatment by activity subgroup, means with different superscript letters differ $(P<0.01)$.

${ }^{1}$ Treatments were (1) cows inseminated based on an activity-monitoring system, with cows not detected with activity receiving TAI after synchronization of ovulation using an Ovsynch protocol; (2) cows inseminated based on an activity-monitoring system after a presynchronization protocol, with cows not detected with activity receiving TAI after synchronization of ovulation using an Ovsynch protocol; and (3) cows receiving TAI after a Presynch-Ovsynch protocol.

cows without activity after presynchronization could have ovulated in the absence of detectable changes in activity and had high P4 concentration at the first GnRH injection of the Ovsynch protocol. Fertility of anovular cows subjected to an Ovsynch protocol is generally about $20 \%$ compared with about $35 \%$ for cycling cows starting Ovsynch at a random stage of the cycle (Gümen et al., 2003; Stevenson et al., 2008). In the present study, cows without activity that received TAI after an Ovsynch protocol had similar P/AI to cycling cows initiating Ovsynch at random stages of their estrous cycles. Our results support a management strategy in which the 30 to $40 \%$ of cows not detected with increased activity are aggressively submitted to an Ovsynch protocol and TAI rather than continuing to detect activity using an activity-monitoring system, thereby delaying first AI.

\section{Economic Comparison Among Treatments}

To account for the effect of treatment on reproductive performance while considering differences in cost among the programs compared, we analyzed the data from the present experiment using a decision-support tool that evaluated the cost and revenue associated with different reproductive management programs under specific conditions particular to each dairy farm (Giordano et al., 2012). According to the conditions stipulated in the simulation scenarios performed, relatively small economic differences were observed between the 3 treatments $(2,728,2,732$, and $2,736 \$ /$ cow per year for treatments 1,2 , and 3 , respectively) assuming that the same management program for second and subsequent AI was used in combination with the 3 first AI strategies. These observations agree with results from the survival analyses, which, in spite of showing differences in the dynamics to first AI (Figure 2), showed no differences among treatments for the percentage of cows pregnant by 300 DIM (Figure 3).

Furthermore, the economics of the scenarios simulated reflect the dynamics of each program with regard to the interaction between service rate and P/AI. The increased AI service rate achieved by inseminating a subgroup of cows to increased activity earlier after the VWP for treatment 1 (56\% of cows) and 2 (70\% of cows) cows was offset by the increase in P/AI observed for treatment-3 cows. Submitting 100\% of treatment-3 cows to TAI yielding $40 \% \mathrm{P} / \mathrm{AI}$ generated more pregnancies than treatment- 1 and -2 cows by 75 DIM, which was only compensated for by the additional pregnancies generated after second and third AI in the other treatments. The relatively minor differences in NPV (4 to $8 \$$ cow per year) for this economic simulation suggests that all 3 strategies are economically viable and could be used alternatively by dairy farms that incorporate an activity-monitoring system for detection of activity and AI. Indeed, changes (reductions for TAI or increases for AI based on activity) in P/AI and (or) the proportion of cows inseminated to increased activity versus TAI may result in the NPV results favoring one strategy over another, as we have demonstrated using economic modeling scenarios (Giordano et al., 2012). Because the proportion of cows inseminated to increased activity versus TAI and the resulting P/AI of cows inseminated to increased activity versus TAI can vary dramatically among individual farms using activity-monitoring systems (Neves et al., 2012), management decisions should be based on an economic analysis using observed reproductive outcomes specific for that individual farm. 


\section{CONCLUSIONS}

Three management strategies for submitting cows for first AI using TAI with or without detection of increased activity for AI using an activity-monitoring system were compared on a commercial dairy farm. Based on survival analysis, although treatment affected the rate at which cows were inseminated, treatment did not affect days to pregnancy from the end of the VWP until 300 DIM. Thus, use of an activity-monitoring system to inseminate cows based on increased activity decreased days to first AI by increasing the AI service rate, whereas cows receiving 100\% TAI after completing a Presynch-Ovsynch protocol had more P/ AI. The trade-off between AI service rate and P/AI was reflected by an economic analysis in which the NPV (\$/ cow per year) was similar among the 3 treatments. We conclude that a variety of strategies using a combination of AI based on increased activity using an activitymonitoring system and synchronization of ovulation and TAI can be used to submit cows for first AI.

\section{ACKNOWLEDGMENTS}

The authors thank Majestic View Dairy (Lancaster, WI) and their staff for the use of their cows and facilities for this experiment. This research was supported by SCR Engineers Ltd. (Netanya, Israel), and Hatch project WIS01171 to P. M. Fricke.

\section{REFERENCES}

Bamber, R. L., G. E. Shook, M. C. Wiltbank, J. E. P. Santos, and P. M. Fricke. 2009. Genetic parameters for anovulation and pregnancy loss in dairy cattle. J. Dairy Sci. 92:5739-5753.

Brusveen, D. J., A. P. Cunha, C. D. Silva, P. M. Cunha, R. A. Sterry, E. P. B. Silva, J. N. Guenther, and M. C. Wiltbank. 2008. Altering the time of the second gonadotropin-releasing hormone injection and artificial insemination (AI) during Ovsynch affects pregnancies per AI in lactating dairy cows. J. Dairy Sci. 91:1044-1052.

Caraviello, D. Z., K. A. Weigel, P. M. Fricke, M. C. Wiltbank, M. J. Florent, N. B. Cook, K. V. Nordlund, N. R. Zwald, and C. L. Rawson. 2006. Survey of management practices on reproductive performance of dairy cattle on large US commercial farms. J. Dairy Sci. 89:4723-4735.

Chebel, R. C., M. J. Al-Hassan, P. M. Fricke, J. E. P. Santos, J. R. Lima, C. A. Martel, J. S. Stevenson, R. Garcia, and R. L. Ax. 2010. Supplementation of progesterone via CIDR inserts during ovulation synchronization protocols in lactating dairy cows. J. Dairy Sci. 93:922-931.

Chebel, R. C., and J. E. P. Santos. 2010. Effect of inseminating cows in estrus following a presynchronization protocol on reproductive and lactation performances. J. Dairy Sci. 93:4632-4643.

Giordano, J. O., A. S. Kalantari, P. M. Fricke, M. C. Wiltbank, and V. E. Cabrera. 2012. A daily herd Markov-chain model to study the reproductive and economic impact of reproductive programs combining timed artificial insemination and estrus detection. J. Dairy Sci. 95:5442-5460.

Gumen, A., A. Keskin, G. Yilmazbas-Mecitoglu, E. Karakaya, A. Alkan, H. Okut, and M. C. Wiltbank. 2012. Effect of a presynchronization strategy before Ovsynch on fertility at first service in lactating dairy cows. Theriogenology 78:1830-1838.

Gümen, A., J. N. Guenther, and M. C. Wiltbank. 2003. Follicular size and response to Ovsynch versus detection of estrus in anovular and ovular lactating dairy cows. J. Dairy Sci. 86:3184-3194.

Holman, A., J. Thompson, J. E. Routly, J. Cameron, D. N. Jones, D. Grove-White, R. F. Smith, and H. Dobson. 2011. Comparison of oestrus detection methods in dairy cattle. Vet. Rec. 169:47.

Jónsson, R., M. Blanke, N. K. Poulsen, F. Caponetti, and S. Højsgaard. 2011. Oestrus detection in dairy cows from activity and lying data using on-line individual models. Comput. Electron. Agric. 76:6-15.

Miller, R. H., H. D. Norman, M. T. Kuhn, J. S. Clay, and J. L. Hutchison. 2007. Voluntary waiting period and adoption of synchronized breeding in dairy herd improvement herds. J. Dairy Sci. 90:1594-1606.

Moreira, F., C. Orlandi, C. A. Risco, R. Mattos, F. Lopes, and W. W. Thatcher. 2001. Effect of presynchronization and bovine somatotropin on pregnancy rates to a timed artificial insemination protocol in lactating dairy cows. J. Dairy Sci. 84:1646-1659.

Neves, R. C., K. E. Leslie, J. S. Walton, and S. J. LeBlanc. 2012. Reproductive performance with an automated activity monitoring system versus a synchronized breeding program. J. Dairy Sci. 95:5683-5693.

NRC. 2001. Nutrient Requirements of Dairy Cattle. 7th ed. Natl. Acad. of Sci., Washington, DC.

Santos, J. E. P., S. O. Juchem, R. L. A. Cerri, K. N. Galvão, R. C. Chebel, W. W. Thatcher, C. S. Dei, and C. R. Bilby. 2004a. Effect of bST and reproductive management on reproductive performance of Holstein dairy cows. J. Dairy Sci. 87:868-881.

Santos, J. E. P., W. W. Thatcher, R. C. Chebel, R. L. A. Cerri, and K. N. Galvão. 2004b. The effect of embryonic death rates in cattle on the efficacy of estrus synchronization programs. Anim. Reprod. Sci. 82-83:513-535.

Silva, E., R. A. Sterry, and P. M. Fricke. 2007. Assessment of a practical method for identifying anovular lactating dairy cows synchronized for first postpartum timed artificial insemination. J. Dairy Sci. 90:3255-3262.

Sterry, R. A., M. L. Welle, and P. M. Fricke. 2006. Treatment with gonadotropin-releasing hormone after first timed AI improves fertility in noncycling lactating dairy cows. J. Dairy Sci. 89:4237-4245.

Stevenson, J. S., and A. P. Phatak. 2005. Inseminations at estrus induced by presynchronization before application of synchronized estrus and ovulation. J. Dairy Sci. 88:399-405.

Stevenson, J. S., D. E. Tenhouse, R. L. Krisher, G. C. Lamb, J. E. Larson, C. R. Dahlen, J. R. Pursley, N. M. Bello, P. M. Fricke, M. C. Wiltbank, D. J. Brusveen, M. Burkhart, R. S. Youngquist, and H. A. Garverick. 2008. Detection of anovulation by heatmount detectors and transrectal ultrasonography before treatment with progesterone in a timed insemination protocol. J. Dairy Sci. 91:2901-2915

Valenza, A., J. O. Giordano, G. Lopes Jr., L. Vincenti, M. C. Amundson, and P. M. Fricke. 2012. Assessment of an accelerometer system for detection of estrus and for treatment with GnRH at the time of insemination in lactating dairy cows. J. Dairy Sci. 95:7115-7127.

Vasconcelos, J. L. M., R. W. Silcox, G. J. M. Rosa, J. R. Pursley, and M. C. Wiltbank. 1999. Synchronization rate, size of the ovulatory follicle, and pregnancy rate after synchronization of ovulation beginning on different days of the estrous cycle in lactating dairy cows. Theriogenology 52:1067-1078. 